\title{
The clock gene PER1 plays an important role in regulating the clock gene network in human oral squamous cell carcinoma cells
}

\author{
Qin Zhao ${ }^{1}$, Gang Zheng', Kai Yang ${ }^{1}$, Yi-ran Ao ${ }^{1}$, Xiao-li Su${ }^{1}$, Yu Li ${ }^{3}$, Xiao-qiang $\mathbf{L v}^{1}$ \\ ${ }^{1}$ Department of Oral and Maxillofacial Surgery, The First Affiliated Hospital of Chongqing Medical University, Yuzhong District, \\ Chongqing 400016, China \\ ${ }^{2}$ Chongqing Traditional Chinese Medicine Hospital, Chongqing 400021, China \\ ${ }^{3}$ Department of Pathology, Chongqing Medical University, Chongqing 400016, China \\ Correspondence to: Kai Yang, email: cafyyk@hotmail.com
}

Keywords: circadian clock, oral cancer, PER 1, gene

Received: June 20, 2016

Accepted: August 26, 2016

Published: September 02, 2016

\section{ABSTRACT}

The various clock genes in normal cells, through their interaction, establish a number of positive and negative feedback loops that compose a network structure. These genes play an important role in regulating normal physiological activities. The expression of clock gene PER1 is decreased in many types of cancer. PER1 is highly correlated with the initiation and progression of cancer by regulating numerous downstream genes. However, it is still unclear whether the lower expression of PER1 in cancer can influence the expression of other clock genes in the clock gene network. In this study, we used short hairpin RNA interference to knock down PER1 effectively in SCC15 human oral squamous cell carcinoma cells. These cancer cells later were subcutaneously injected into the back of nude mice. We discovered that after PER1 knockdown, apoptosis was decreased and cell proliferation and in vivo tumor formation were enhanced. Quantitative real-time PCR result indicated that in vitro and in vivo cancer cells after PER1 knockdown, PER2, DEC1, DEC2, CRY1, CRY2 and NPAS2 were significantly down-regulated at the mRNA level, while PER3, $T I M, R O R a$ and $R E V$-ERBa were significantly up-regulated. It prompts that the role of PER1 in carcinogenesis is exerted not only by regulating downstream genes, but also through the synergistic dysregulation of many other clock genes in the clock gene network.

\section{INTRODUCTION}

Circadian clock, is present in the human body, has important effects on the tightly organized regulation of various complex physiological processes [1,2]. The clock genes are the core structure of circadian clock. To date, 14 clock genes have been identified: CLOCK, BMAL1, PER1, PER2, PER3, DEC1, DEC2, CRY1, CRY2, TIM, $C K I E, R O R \alpha$, NPAS2 and REV-ERB $\alpha$ [2-10], which are nearly ubiquitously expressed in humans $[11,12]$. The clock genes interact and form networks through a set of positive and negative feedback loops at the transcriptional and translational levels. These genes form the clock gene networks through interaction [3-8]. About 2-10\% of mammalian genes are regulated genome-wide by the products of these clock genes, which are known as clock-controlled genes (CCGs) [3, 13, 14]. As Zhang et al. reported $43 \%$ of all protein coding genes are CCGs [15]. Different clock genes can affect cellular activities by regulating the expression of several downstream CCGs [3]. The abnormal expression of clock genes is significant causes that lead to the occurrence and progression of many diseases, including cancer, cardiovascular disease, diabetes and depression $[3,9,16]$.

Period 1 (PER1) is an important circadian clock gene $[4,5]$. Recent reports have indicated that PERI expression is decreased in a series of solid carcinomas, such as head-neck carcinoma, prostatic cancer, breast cancer, colorectal cancer, and endometrial cancer [17-20]. PERI can regulate downstream cell cycle genes. In addition, reduced mRNA expression of PERI can lead to an imbalance between cell proliferation and apoptosis, 
further promoting malignant cell transformation $[9,10$, $18,21-23]$. We previously demonstrated that mRNA and protein expression of PER1 are remarkably reduced in oral squamous cell carcinoma (OSCC) compared to para-carcinoma tissue [17]. We also illustrated that PER1 knockdown in OSCC cells SCC15 results in altered expression of numerous downstream cell cycle genes and cancer-related genes, which enhanced proliferation and metastasis of cancer cell [24]. Above all, it is universally accepted that decreased PERI expression in cancer closely correlates with tumor occurrence and progression by regulating downstream cell cycle genes and cancerrelated genes, including Cyclin B1, Cyclin D, Cyclin E, WEE-1, C-MYC, KI-67, MDM2, and p53 [12, 18, 24]. PER1 gene is one of the most important components in the clock gene network. However, it is still unclear whether reduced PER1 expression in carcinoma cells can affect the normal expression of other clock genes in the inherent network. Here, we used short hairpin RNA (shRNA) interference to effectively knockdown PER1 in SCC15 human OSCC cells. We demonstrated that in vitro and in vivo cancer cells after PER1 knockdown, PER2, DEC1, $D E C 2, C R Y 1, C R Y 2$ and NPAS2 were significantly downregulated at the mRNA level, while PER3,TIM, ROR $\alpha$ and $R E V-E R B \alpha$ were significantly up-regulated. In addition, we determined that apoptosis was decreased, whereas cell proliferation and tumor formation were enhanced, after PER1 knockdown in vitro and in vivo. Our findings prompt that the effect of PERI on tumor occurrence and progression is not only achieved by regulating downstream CCGs, but also through the synergistic modulation of other clock genes in the network.

\section{RESULTS}

\section{Construction and sequencing of lentivirus shRNA plasmids}

DNA sequencing results of the lentiviral PERshRNA-I III plasmids are reported in Supplementary Figure S1 and Supplementary Table S1. The plasmid sequences exactly matched the oligonucleotide interference target sequences of positive-sense strands of PER-shRNA-I III, indicating that three shRNAs targeting PER1 were successfully constructed.

\section{Expression of PER1 mRNA and protein in tumor cells}

qRT-PCR analysis showed that in the three PER1-shRNA-I III groups, Control-shRNA group, and untreated SCC15 cells, mRNA expression of PER1 normalized to the level of $\beta$-actin mRNA were $0.22 \pm 0.05, \quad 0.56 \pm 0.07, \quad 0.63 \pm 0.11, \quad 0.94 \pm 0.20 \quad$ and $1.12 \pm 0.10$, respectively. Western blot data indicated that the relative level of PER 1 protein normalized to the level of GAPDH protein was $0.18 \pm 0.07,0.61 \pm 0.06,0.56 \pm 0.06$, $1.14 \pm 0.05$ and $1.18 \pm 0.13$, respectively. The expression of PER1-shRNA-I was significantly reduced both at the mRNA and protein levels, compared to the other groups $(P<0.05)$ (Figure 1). This demonstrates that PERl was most effectively knocked down in PER1-shRNA-I group. Therefore, we chose to use this shRNA for the following experiments.

\section{Proliferation and apoptosis of SCC15 cells in vitro after PER1 knockdown}

Flow cytometry analysis indicated that the cell proliferation index of the cells expressing PER1shRNA-I (49.21 $\pm 3.75 \%)$ was significantly higher than for cells expressing Control-shRNA $(39.99 \pm 3.19 \%)$ or untreated SCC15 cells $(40.09 \pm 3.82 \%)(P<0.05)$. The cell apoptosis index of the cells expressing PER1-shRNA-I $(16.61 \pm 1.37 \%)$ was significantly lower than for cells expressing Control-shRNA $(21.26 \pm 1.90 \%)$ or untreated SCC15 cells $(20.86 \pm 2.00 \%)(P<0.05)$. In contrast, no difference was noted between the Control-shRNA group and the SCC15 group either in the proliferation index or in the apoptosis index $(P>0.05)$ (Figure 2).

\section{mRNA expression levels of clock genes in SCC15 cells after PER1 knockdown in vitro}

qRT-PCR analysis demonstrated that the mRNA expression of PER3, TIM, ROR $\alpha$ and REV-ERB $\alpha$ was significantly up-regulated in the PER1-shRNA-I group when compared to the Control-shRNA and SCC15 groups $(P<0.05)$. In contrast, the mRNA expression of PER2, DEC1, DEC2, CRY1, CRY2 and NPAS2 was significantly down-regulated $(P<0.05)$. There was no notable difference between the Control-shRNA and SCC15 groups $(P>0.05)$. In addition, there was no difference in the mRNA expression of CLOCK, BMAL1 and CKI $\varepsilon$ among the three groups $(P>0.05)$ (Table 1 and Figure 3$)$.

\section{Tumorigenesis assay in nude mice in vivo}

All of the ten nude mice survived and presented tumor growth. The tumor weights in the PER1-shRNA-I and Control-shRNA groups were, respectively, $(0.55 \pm 0.13)$ $\mathrm{g}$ and $(0.27 \pm 0.05) \mathrm{g}$. The tumor volumes in the PER1shRNA-I and Control-shRNA groups were, respectively, $(0.24 \pm 0.10) \mathrm{cm}^{3}$ and $(0.07 \pm 0.03) \mathrm{cm}^{3}$. The average weight and volume of transplanted tumors from nude mice in the PER1-shRNA-I group was significantly increased compared to the Control-shRNA group $(P<0.05)$. They appeared as squamous cell carcinoma by HE staining of tumor slices observed under an optical microscope $(200 \times)$ (Figure 4). 
A

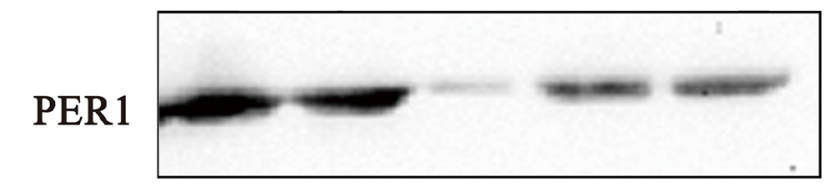

GAPDH
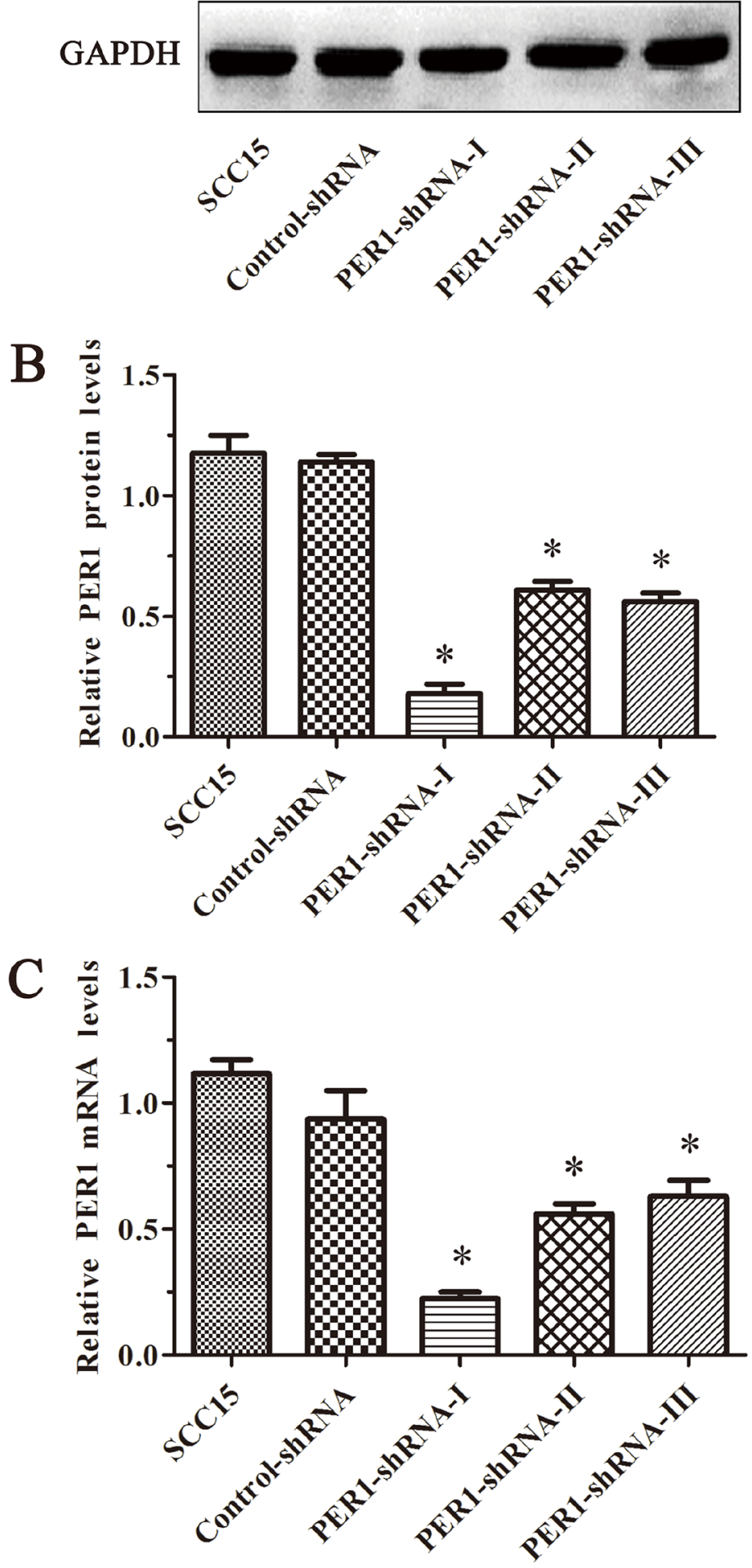

Figure 1: PER1 is most efficiently knocked down in the PER1-shRNA-I group among five groups of SCC15 cells. A. Levels of PER1 protein in the SCC15, Control-shRNA and PER1-shRNA-I-III groups. B. Levels of PER1 protein were significantly reduced in SCC15 cells transfected with PER1-shRNA-I. C. Expression of PER1 mRNA was significantly down-regulated in SCC15 cells transfected with PER1-shRNA-I. Data are presented as the mean \pm SD. Significant differences between multiple groups were evaluated using ANOVA; differences between two groups were evaluated using the LSD test. ${ }^{*} P<0.05$ was considered statistically significant. 


\section{Proliferation and apoptosis of tumor cells after PER1 knockdown in vivo}

The in vivo cell proliferation index of cells expressing PER1-shRNA-I (47.96 $\pm 3.69 \%)$ was significantly higher than for cells expressing ControlshRNA $(40.22 \pm 2.45 \%)(P<0.05)$. The in vivo cell apoptosis index of cells expressing PER1-shRNA-I $(16.78 \pm 1.39 \%)$ was significantly lower than for cells expressing Control-shRNA $(21.64 \pm 1.75 \%) \quad(P<0.05)$ (Figure 5). These results indicate that the alterations in proliferation and apoptosis of SCC15 cells in vivo are in accordance with the in vitro data observed after PERI knockdown.

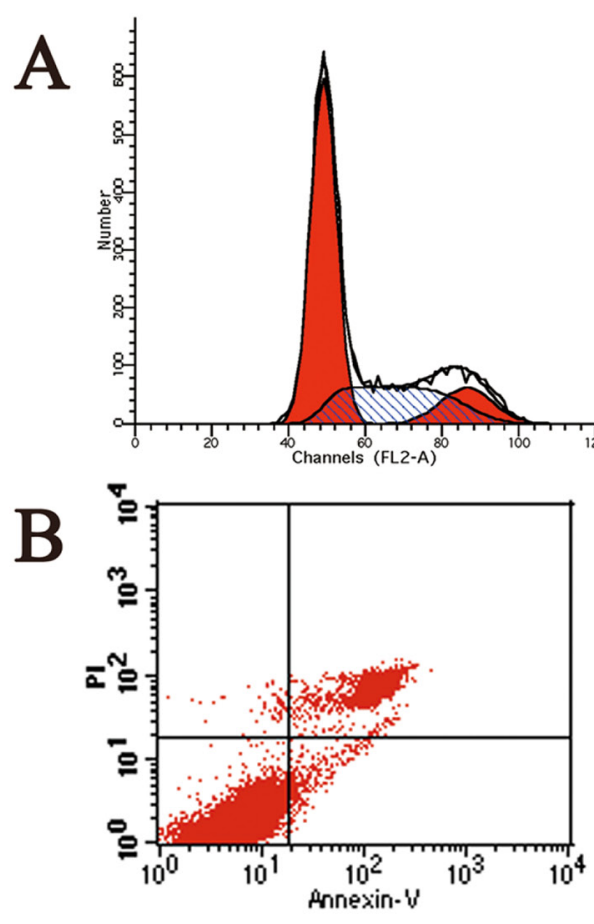

SCC15
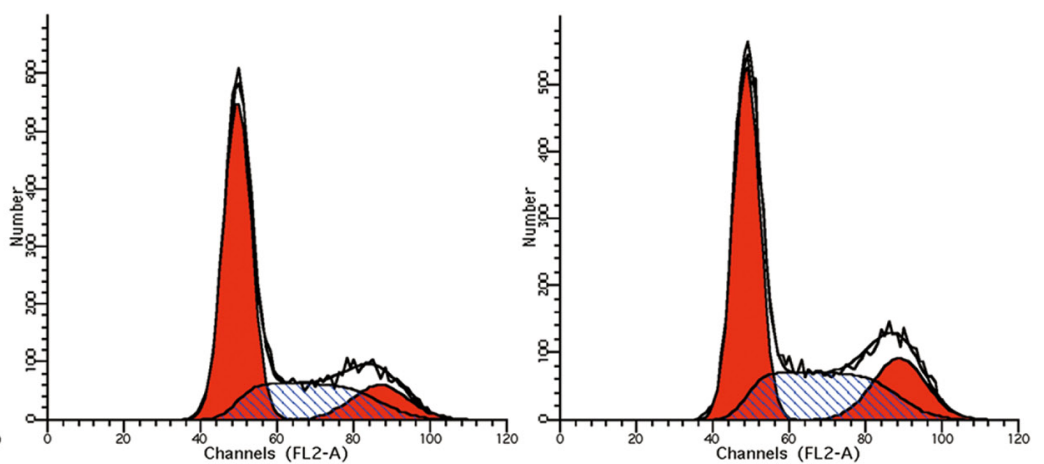

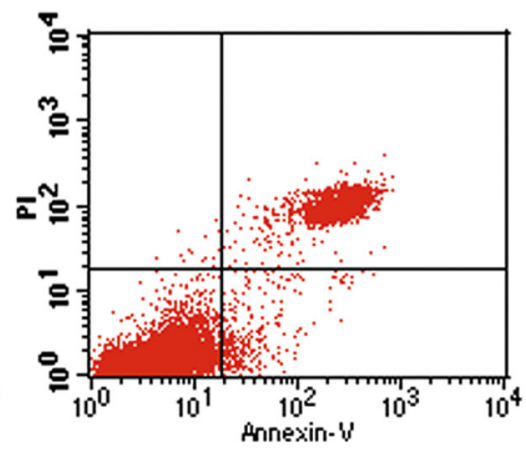

Control-shRNA

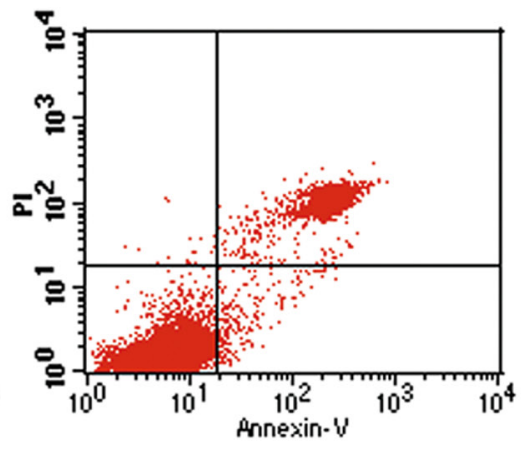

PER1-shRNA-I
$\mathrm{C}$

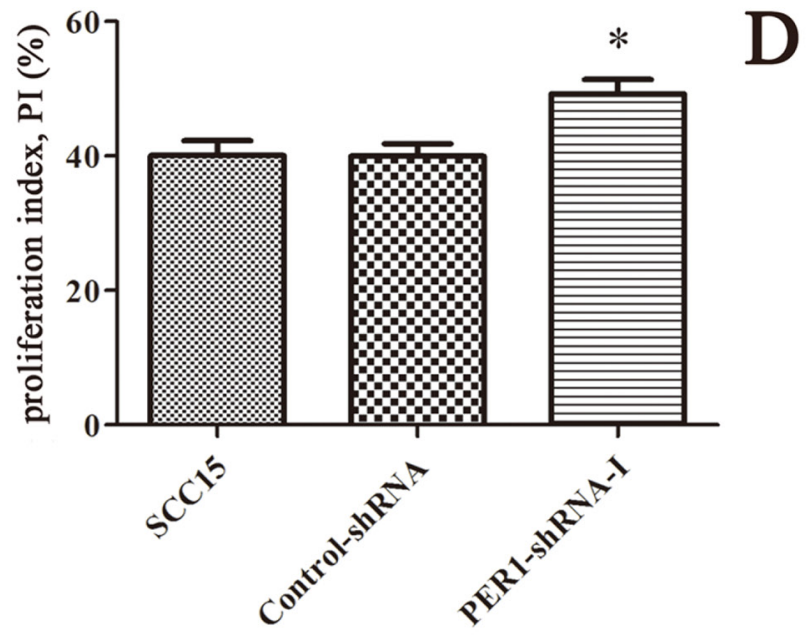

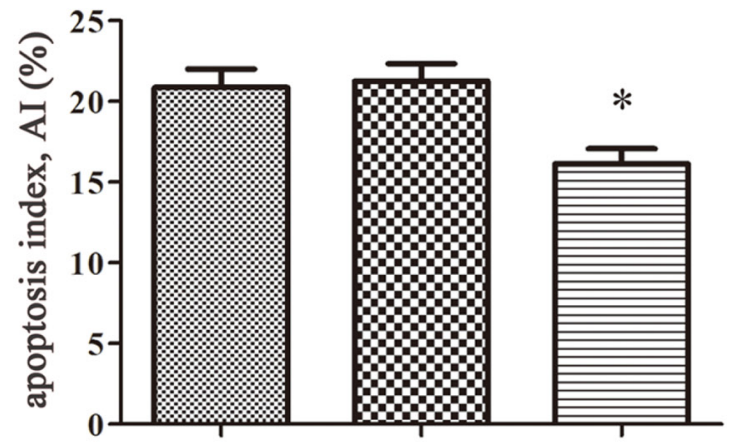

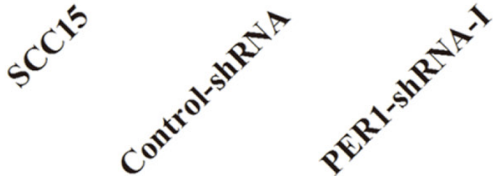

Figure 2: PER1 knockdown enhances proliferation and reduces apoptosis of SCC15 cells in vitro. A. Representative flow cytometry profiles of proliferation among cells in the SCC15, Control-shRNA and PER1-shRNA-I groups. B. Representative flow cytometry profiles of apoptosis among cells in the SCC15, Control-shRNA and PER1-shRNA-I groups. C. The proliferation index was significantly increased in SCC15 cells transfected with PER1-shRNA-I in vitro. D. The apoptosis index was significantly reduced in SCC15 cells transfected with PER1-shRNA-I in vitro. Data are presented as the mean \pm SD. Differences between multiple groups were evaluated using ANOVA; differences between two groups were evaluated using the LSD test. ${ }^{*} P<0.05$ was considered statistically significant. 
Table 1: Levels of mRNA expression of clock genes in the PER1-shRNA-I, Control-shRNA and SCC15 groups in vitro $($ mean $\pm \mathrm{SD})$

\begin{tabular}{lcccccccc}
\hline Gene & $\begin{array}{c}\text { PER1- } \\
\text { ShRNA-I }\end{array}$ & Control-shRNA & SCC15 & F & $\boldsymbol{P}$ & $\boldsymbol{P}_{1}$ & $\boldsymbol{P}_{2}$ & $\boldsymbol{P}_{3}$ \\
\hline PER1 & $0.25 \pm 0.09$ & 1.00 & $1.23 \pm 0.29$ & 26.09 & 0.001 & 0.002 & 0.000 & 0.156 \\
PER2 & $0.52 \pm 0.09$ & 1.00 & $0.99 \pm 0.05$ & 64.24 & 0.000 & 0.000 & 0.000 & 0.871 \\
PER3 & $1.28 \pm 0.11$ & 1.00 & $0.92 \pm 0.09$ & 14.64 & 0.005 & 0.007 & 0.002 & 0.259 \\
DEC1 & $0.65 \pm 0.08$ & 1.00 & $1.05 \pm 0.02$ & 56.02 & 0.000 & 0.000 & 0.000 & 0.293 \\
DEC2 & $0.51 \pm 0.06$ & 1.00 & $1.03 \pm 0.11$ & 50.21 & 0.000 & 0.000 & 0.000 & 0.665 \\
CRY1 & $0.82 \pm 0.09$ & 1.00 & $1.05 \pm 0.05$ & 12.34 & 0.007 & 0.011 & 0.003 & 0.317 \\
CRY2 & $0.70 \pm 0.05$ & 1.00 & $1.03 \pm 0.05$ & 53.08 & 0.000 & 0.000 & 0.000 & 0.476 \\
TIM & $1.36 \pm 0.07$ & 1.00 & $0.97 \pm 0.03$ & 87.12 & 0.000 & 0.000 & 0.000 & 0.401 \\
ROR $\alpha$ & $2.02 \pm 0.66$ & 1.00 & $1.16 \pm 0.14$ & 6.05 & 0.036 & 0.018 & 0.034 & 0.639 \\
NPAS2 & $0.67 \pm 0.04$ & 1.00 & $1.03 \pm 0.08$ & 44.36 & 0.000 & 0.000 & 0.000 & 0.469 \\
REV-ERB & $1.59 \pm 0.14$ & 1.00 & $1.04 \pm 0.18$ & 19.55 & 0.002 & 0.001 & 0.002 & 0.695 \\
CLOCK & $0.99 \pm 0.08$ & 1.00 & $1.00 \pm 0.05$ & 0.04 & 0.964 & 0.801 & 0.856 & 0.943 \\
BMAL1 & $0.98 \pm 0.07$ & 1.00 & $0.95 \pm 0.09$ & 0.37 & 0.705 & 0.693 & 0.670 & 0.422 \\
CKIE & $0.97 \pm 0.10$ & 1.00 & $1.06 \pm 0.10$ & 1.00 & 0.421 & 0.630 & 0.212 & 0.408 \\
\hline
\end{tabular}

Notes: $P$ values reflect differences in each gene expression among the three groups analyzed using one-way ANOVA. $P_{1}, P_{2}$, and $P_{3}$ respectively reflect the intergroup differences between the PER1-shRNA-I and Control-shRNA groups, the PER1-shRNA-I and SCC15 groups, and the Control-shRNA and SCC15 groups analyzed using the LSD test after one-way ANOVA. Values of $P<0.05$ were considered statistically significant.

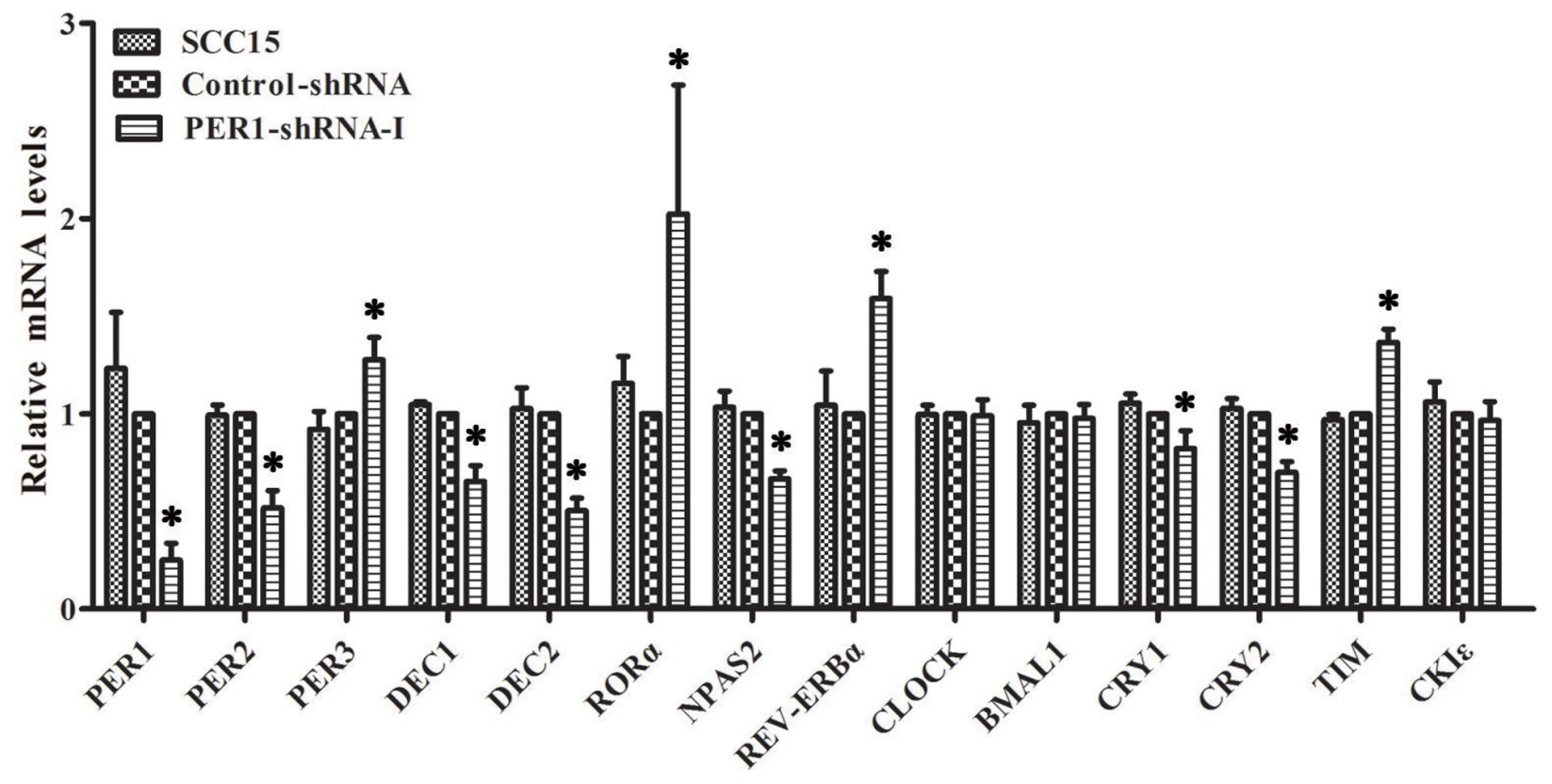

Figure 3: Levels of mRNA expression of clock genes in SCC15 cells after PER1 knockdown in vitro. mRNA expression of PER3, TIM, ROR $\alpha$ and REV-ERB $\alpha$ was significantly up-regulated in the PER1-shRNA-I group as compared to the Control-shRNA and SCC15 groups, while mRNA expression of PER2, DEC1, DEC2, CRY1, CRY2 and NPAS2 was significantly down-regulated. There was no notable difference between the Control-shRNA and SCC15 groups. In addition, there was no difference in mRNA expression of CLOCK, BMAL1 and CKI $\varepsilon$ among the three groups. Data are presented as the mean \pm SD. Differences between multiple groups were evaluated using ANOVA; differences between two groups were evaluated using the LSD test. ${ }^{*} P<0.05$ was considered statistically significant. 
mRNA expression of clock genes in cancer cells after PER1 knockdown in vivo

qRT-PCR analysis showed that the mRNA expression of PER1, PER2, DEC1, DEC2, CRY1, CRY2 and NPAS2 was significantly down-regulated in vivo in the PER-shRNA-I group as compared to the ControlshRNA group tumors $(P<0.05)$, while mRNA expression of PER3, TIM, ROR $\alpha$ and REV-ERB $\alpha$ was significantly up-regulated $(P<0.05)$, and mRNA expression of CLOCK, BMAL1 and CKI $\varepsilon$ had no obvious change among the two groups $(P>0.05)$ (Table 2 and Figure 6). These

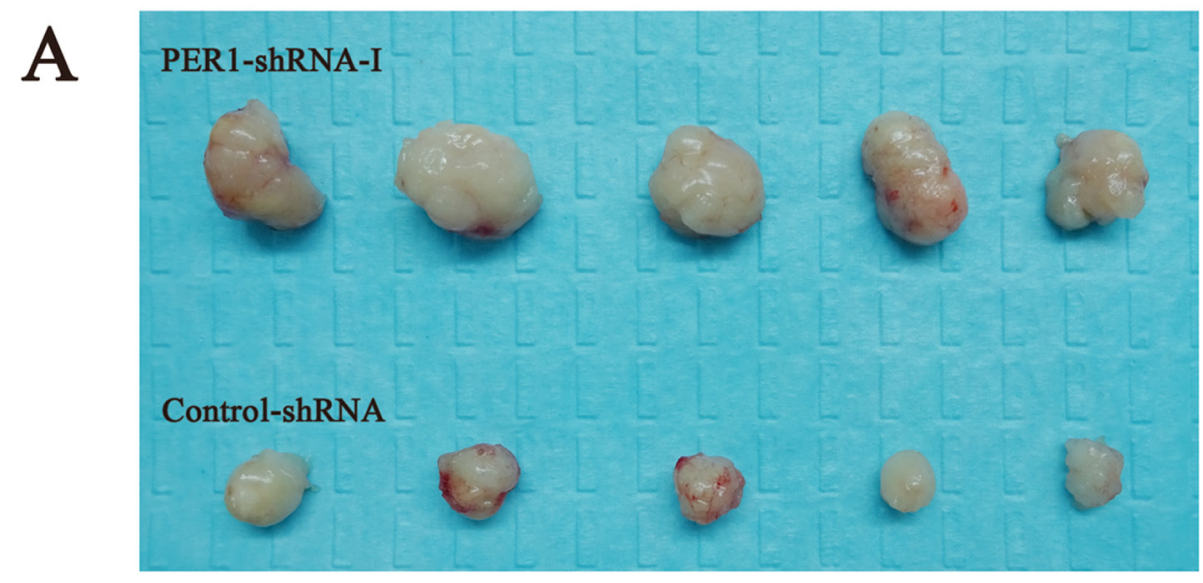

B

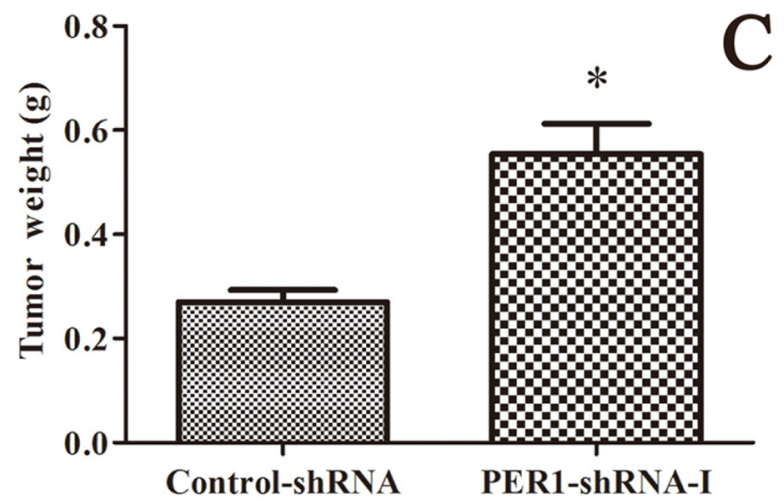

$\mathrm{D}$

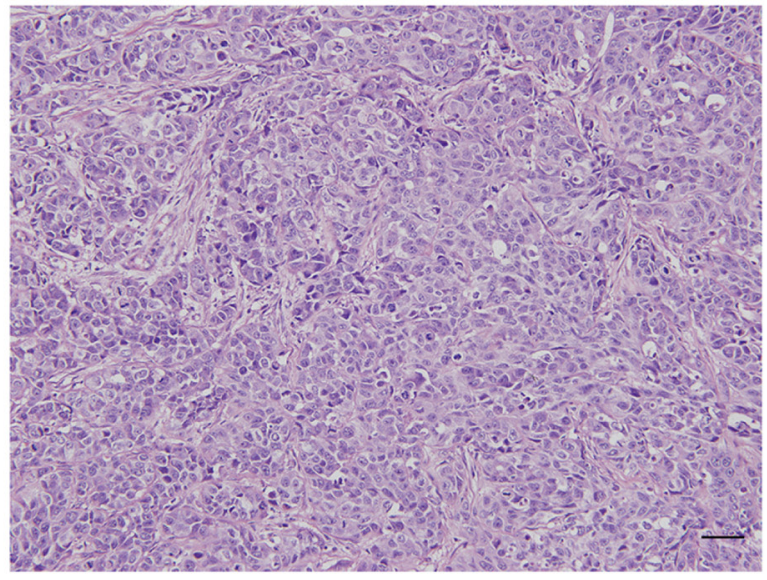

Control-shRNA
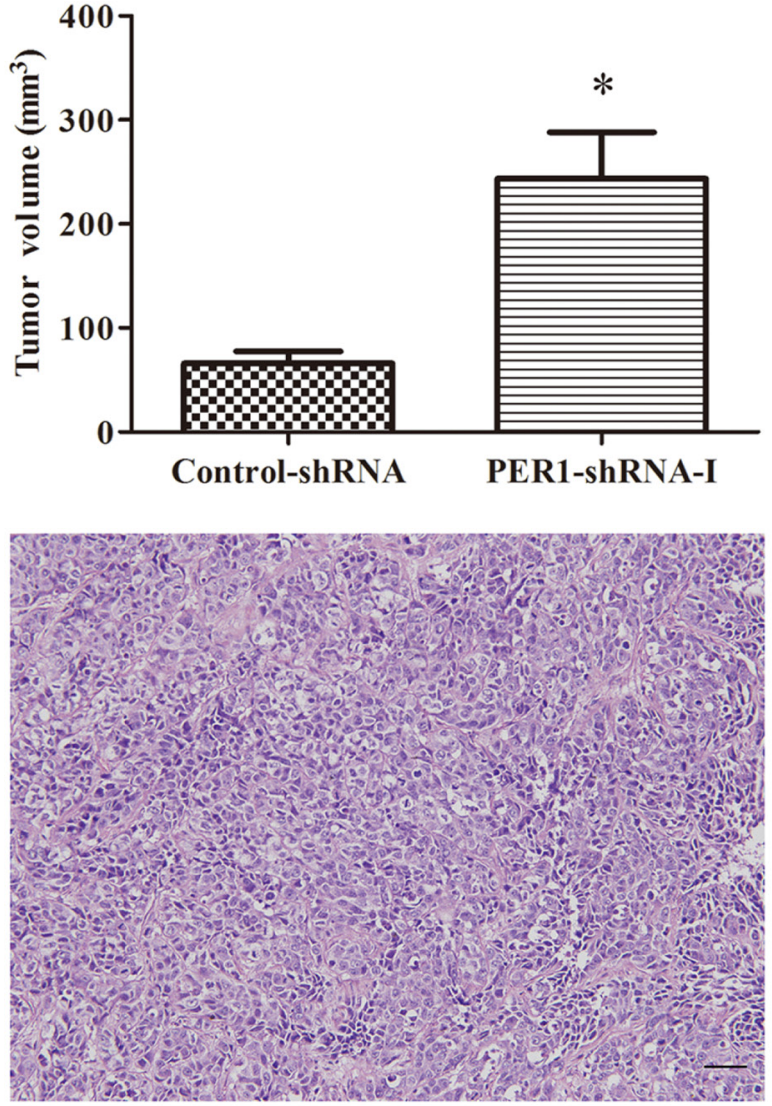

PER1-shRNA-I

Figure 4: PER1 knockdown enhances the tumorigenic capacity of SCC15 cells in vivo. A. The condition of tumorigenesis in vivo including PER1-shRNA-I and Control-shRNA group cells. B and C. Average weight and volume of transplanted tumors from nude mice were significantly increased after PERI knockdown. D. HE staining of tumor tissue slices in the PER1-shRNA-I and Control-shRNA group were observed under an optical microscope $(200 \times)$. Data are presented as the mean \pm SD, Student's t-test was used to analyze the significance of differences. ${ }^{*} P<0.05$ was considered statistically significant. 
observations suggest that the mRNA expression patterns of clock genes in SCC15 cancer cells are similar in vitro and in vivo.

\section{DISCUSSION}

Previous studies have demonstrated that the expression of PER 1 is decreased in many types of cancer. Further, PER1 is able to regulate numerous downstream cell cycle genes and cancer-related genes that act as CCGs, thereby it has a close relationship with tumor occurrence and progression [12, 17-20, 24]. PER1 is an important circadian clock gene $[4,5]$, this study demonstrates that PERl also has an important role in regulating the clock gene network.

Recent studies have demonstrated that in normal cells the clock genes mainly create networks through three feedback loops at the transcriptional and translational levels. Positive feedback factors of these three loops are CLOCK/BMAL1 heterodimers, which serve as transcription factors to activate the transcription of PERs, CRYs, DECs, REV-ERB $\alpha$ and ROR $\alpha$ genes and promote their expression, thus generating the positive feedback pathway. In contrast, PERs and CRYs proteins form heterodimers and translocate into the nucleus to get feedback on inhibiting and reducing the transcriptional activation of CLOCK/BMAL1 through combining with it, thus generating the first negative feedback pathway.
In the next place, DEC1 and DEC2 form hetero- or homodimers, as the transcription factor, which translocate into the nucleus to reduce the transcriptional activation of CLOCK/BMAL1 heterodimers competitively, and generate the second negative feedback pathway. Finally, $\mathrm{REV}-\mathrm{ERB} \alpha$ and $\mathrm{ROR} \alpha$ proteins translocate into the nucleus to repress and promote $B M A L 1$ expression as the transcription factor respectively, thus representing the third negative feedback pathway [4-8]. In our research, we found no marked alterations in the mRNA expression of CLOCK and BMAL1 after PER1 knockdown in SCC15 cells, suggesting that $C L O C K$ and $B M A L 1$ are not subject to PER 1 regulation at the transcriptional level. Lee et al. [25] reported that CLOCK/BMAL1 remain steady during circadian feedback loops in mammalian liver normal cells. As a transcriptional regulation factor, CLOCK/BMAL1 plays the positive regulating role by nuclear translocation. Hence, we speculate that the lower expression of PER1 in cancer cells can influence the activation and the intracellular distribution of CLOCK/BMAL1, rather than the alteration in expression level.

Based on the above feedback loops in normal cells, when the expression of PERI decreased, reducing the inhibitory effect of the positive transcriptional regulator CLOCK/BMAL1 heterodimer, as a result, increasing the transcriptional activation of CLOCK/ BMAL1 and the expression of negatively regulated genes, including PER2, PER3, CRY1, CRY2, DEC1,
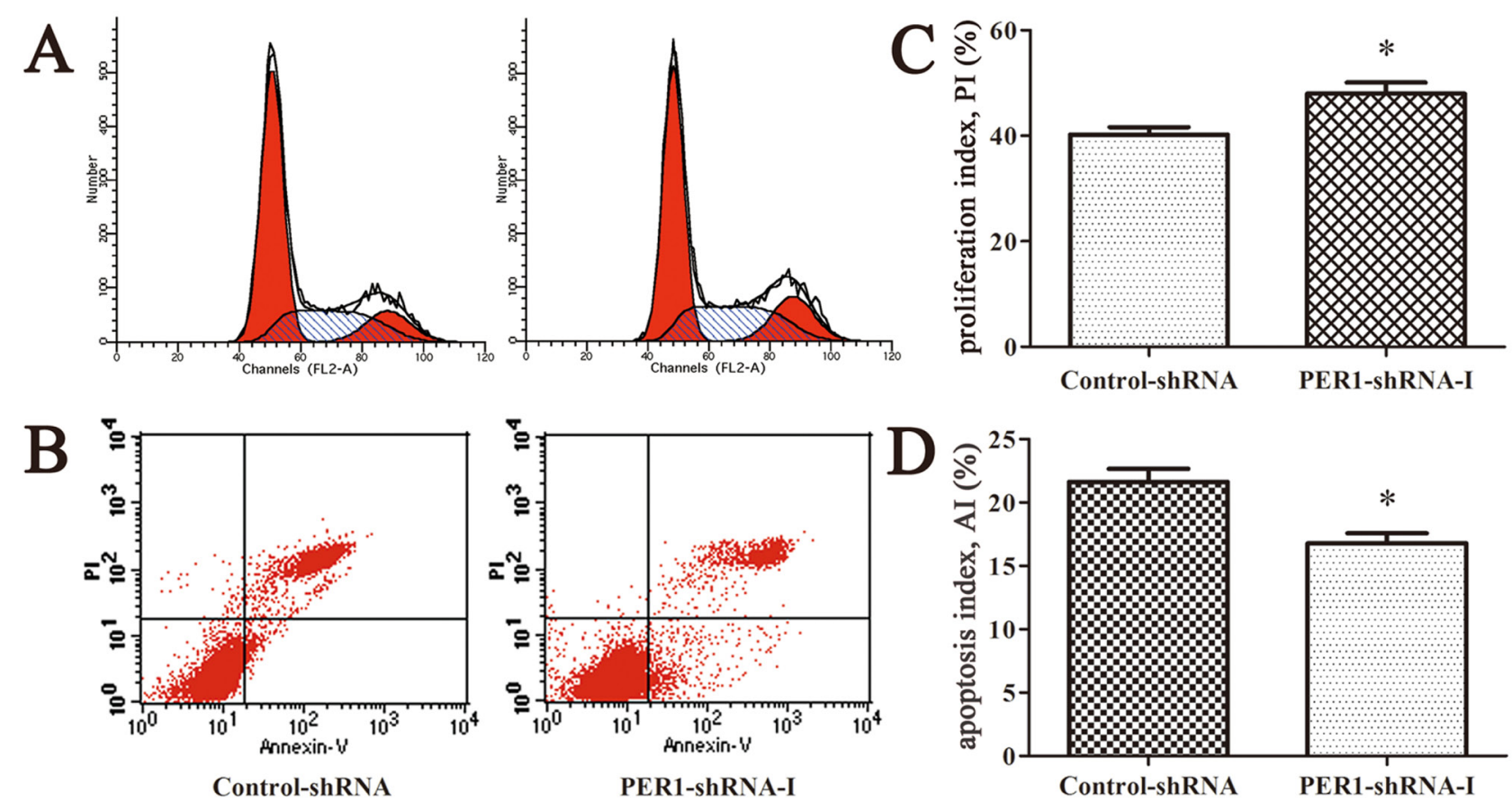

Figure 5: PER1 knockdown enhances proliferation and reduces apoptosis of SCC15 cells in vivo. A. Representative flow cytometry profiles of proliferation among tumor tissues in the Control-shRNA and PER1-shRNA-I groups. B. Representative flow cytometry profiles of apoptosis among tumor tissue in the Control-shRNA and PER1-shRNA-I groups. C. The proliferation index was significantly increased in SCC15 cells transfected with PER1-shRNA-I in vivo. D. The apoptosis index was significantly reduced in SCC15 cells transfected with PER1-shRNA-I in vivo. Data are presented as the mean \pm SD. Student's t-test was used to analyze the significance of differences. $* P<0.05$ was considered statistically significant. 
Table 2: Levels of mRNA expression of clock genes in the PER1-shRNA-I and Control-shRNA tumor cell groups in vivo (mean $\pm \mathrm{SD})$

\begin{tabular}{lcccc}
\hline Gene & PER1-shRNA-I & Control-shRNA & F & P \\
\hline PER1 & $0.33 \pm 0.07$ & 1.00 & 312.75 & 0.000 \\
PER2 & $0.49 \pm 0.08$ & 1.00 & 117.74 & 0.000 \\
PER3 & $1.45 \pm 0.05$ & 1.00 & 268.64 & 0.000 \\
DEC1 & $0.59 \pm 0.04$ & 1.00 & 392.11 & 0.000 \\
DEC2 & $0.58 \pm 0.03$ & 1.00 & 654.31 & 0.000 \\
CRY1 & $0.70 \pm 0.07$ & 1.00 & 51.68 & 0.002 \\
CRY2 & $0.81 \pm 0.04$ & 1.00 & 55.25 & 0.002 \\
TIM & $1.36 \pm 0.21$ & 1.00 & 9.07 & 0.040 \\
ROR 2 & $1.89 \pm 0.25$ & 1.00 & 37.99 & 0.004 \\
NPAS2 & $0.53 \pm 0.05$ & 1.00 & 288.10 & 0.000 \\
REV-ERB & $1.59 \pm 0.30$ & 1.00 & 12.10 & 0.025 \\
CLOCK & $1.02 \pm 0.14$ & 1.00 & 0.04 & 0.861 \\
BMAL1 & $0.97 \pm 0.10$ & 1.00 & 0.23 & 0.657 \\
CKIE & $1.06 \pm 0.10$ & 1.00 & 1.11 & 0.352 \\
\hline
\end{tabular}

Notes: $P$ values reflect differences in each gene expression among the PER1-shRNA-I and Control-shRNA groups analyzed using student's t-test. Values of $P<0.05$ were considered statistically significant.

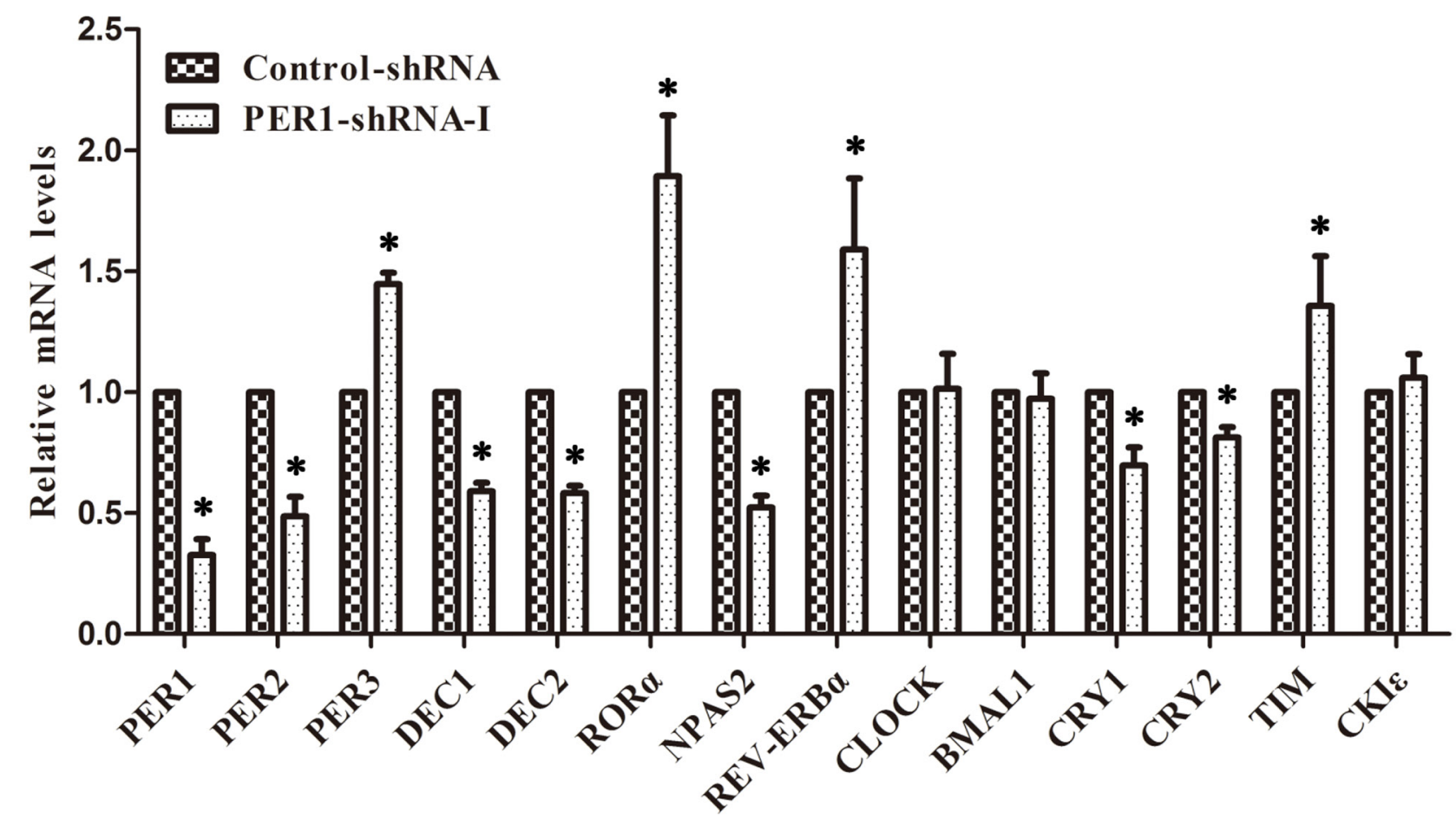

Figure 6: Levels of mRNA expression of clock genes after PER1 knockdown in vivo (mean \pm SD). mRNA expression of PER3, TIM, ROR $\alpha$ and REV-ERB $\alpha$ was significantly up-regulated in the PER1-shRNA-I group as compared to the Control-shRNA, while mRNA expression of PER2, DEC1, DEC2, CRY1, CRY2 and NPAS2 was significantly down-regulated. There was no difference in mRNA expression of CLOCK, BMAL1 and CKI $\varepsilon$ among the two groups. Data are presented as the mean $\pm \mathrm{SD}$. Student's t-test was used to analyze the significance of differences. ${ }^{*} P<0.05$ was considered statistically significant. 
$D E C 2, R E V-E R B \alpha$ and $R O R \alpha$. Zheng et al. reported that in PER1 mutant mice, PER2 protein expression was increased [11]. Further, Jacob and colleagues [26] demonstrated that PERI knockdown in mouse liver and endothelial normal cells resulted in the up-regulation of CRY2 at the mRNA and protein levels. However, our in vitro and in vivo experiments demonstrated that after PER1 knockdown in SCC15 cells, only the expression of PER3, ROR $\alpha$ and $R E V-E R B \alpha$ increased among the negatively regulated genes, in agreement with previously identified mechanisms of the positive and negative circadian feedback regulation in normal cells. The mRNA expression of other negatively regulated genes, including $P E R 2, C R Y 1, C R Y 2, D E C 1$ and $D E C 2$, was markedly decreased, in contrast with the typical responses observed for the positive and negative circadian feedback regulation in normal cells. We speculated the reason may be that previous experiments were all performed in normal cells, while our research was performed in cancer cells. We might assume that the regulatory functions of the positive and negative circadian feedback loop network in cancer cells may be distinct from that in normal cells, or there might exist additional complementary regulatory processes in cancer cells. Moreover, there may exist other mechanisms in cancer cells to regulate the expression of clock genes, leading to the abnormal feedback loops of clock genes. For instance, Kuo and Clark el. proved that promoters of these clock genes (PER1, PER2, PER3, CRY1 and $C R Y 2)$ were methylated in a variety of cancer cells, which resulted in their decreased expression [27, 28]. The above problems need to be further in-depth study.

We also found that after PERl knockdown in SCC15 cells, mRNA expression of TIM and NPAS2 were greatly increased or decreased, respectively. TIM has not been included in the circadian feedback loops of normal cells so far [4-8]. We determined that the mRNA expression of TIM was increased after PERl knockdown in cancer cells, indicating that TIM may either serve as a factor in the circadian feedback loops of cancer cells. NPAS2 is a paralog of CLOCK that can dimerize with BMAL1 to form NPAS2/BMAL1 heterodimers, which have a similar function to CLOCK/BMAL1 [29], and it appears to have a compensatory effect on CLOCK/ BMAL1 [30]. In our research, mRNA expression of NPAS2 was robustly decreased after PER1 knockdown, indicating that the compensatory effect on CLOCK/ BMAL1 was weakened due to PER1 knockdown in cancer cells.

At present, it is recognized that altered PER 1 expression could result in altered expression of downstream cell cycle genes and cancer-related genes, thus leading to the occurrence of tumors [12, 18, 24]. Our study clarifies that PER 1 has an important role in regulating the clock gene network, and for the first time finds that the regulation function has a large difference between normal cells and cancer cells. This study demonstrates that the down-regulation of PER1 in cancer cells can result in the robust up-regulation of PER3, TIM, $R O R \alpha$ and $R E V-E R B \alpha$ transcripts, while the expression of PER2, DEC1,DEC2, CRY1, CRY2 and NPAS2 is prominently down-regulated in vitro and in vivo. We also determined that apoptosis was decreased and cell proliferation and tumor formation were enhanced after PER1 knockdown in vitro and in vivo. Our research prompts that the role of PER 1 on tumor occurrence and progression is not only exerted by regulating downstream CCGs, but also by simultaneously modulating the expression of many other clock genes in the clock gene network. However, our research only concentrated on the transcriptional level. Future studies will need to concentrate on the translational and post-translational levels, to further illustrate the molecular function and the regulatory effects in the clock gene network and the tumor suppression mechanisms of PER1, providing new and effective molecular targets for the treatment of cancers.

\section{MATERIALS AND METHODS}

\section{Construction and identification of lentivirus shRNA plasmids}

shRNA target sequences for PERl were selected by contrast and screening principles [31] on the basis of the GenBank mRNA sequence encoding hPER1 (NM_002616.2), (PER1-I, CAGCACCACT AAGCGTAAATG; PER1-II, CCAGCACCACTAAGCGT AAAT; PER1-III, CCATGGACATGTCCACCTATA). Then, using the design principles for RNA interference [31], three pairs of shRNA plasmids targeting PER1 (PER1-shRNA-I, PER1-shRNA-II and PER1-shRNA-III) were designed (Table 3). Restriction enzyme digestion with AgeI and EcoRI (NEB, Ipswich, Massachusetts, USA) was used to linearize the vector plasmid PLKO.1 after gel electrophoresis. Next, we incubated the PER1-shRNA-I III annealing primers with T4 DNA Ligase, to construct the lentiviral PER1-shRNAI III plasmids. The scramble shRNA 5'-CCTAAGGTTAA GTCGCCCTCGCTCGAGCGAGGGCGACTTAACCTTA GG-3' (Sigma-Aldrich, St. Louis, MO, USA), which had no predicted interference effects on any genes, served as the control (Control-shRNA). These vectors were then transformed into freshly prepared Escherichia coli DH5 $\alpha$ cells (Sangon Biotech, Shanghai, China). Bacterial colonies were then selected in LB medium with Amino nucleoside antibiotic and cultured at $37^{\circ} \mathrm{C}$ overnight. Plasmids were extracted using a QIAGEN Plasmid Midi Kit (Qiagen, Germany), and the amplification products produced by PCR were analyzed by DNA sequencing using the Chromas v2.4 program (Technelysium, Australia). 
Table 3: Sequences of PER1-shRNAs

\begin{tabular}{lll}
\hline Group & Sense strand & Antisense Strand \\
\hline PER1-shRNA-I & 5'-CCGGCAGCACCACTAAGCGTAAATG & 5'-AATTCAAAAACAGCACCACTAAGCGTA \\
& CTCGAGCATTTACGCTTAGTGGTGCTGT & AATGCTCGAGCATTTACGCTTAGTGGTGC \\
& TTTTG-3' & TG-3' \\
PER1-shRNA-II & 5'-CCGGCCAGCACCACTAAGCGTAAATCT & 5'-AATTCAAAAACCAGCACCACTAAGCGT \\
& CGAGATTTACGCTTAGTGGTGCTGGTTTT & AAATCTCGAGATTTACGCTTAGTGGTGCT \\
& TG-3' & GG-3' \\
PER1-shRNA-III & 5'-CCGGCCATGGACATGTCCACCTATACT & 5'-AATTCAAAAACCATGGACATGTCCACCTA \\
& CGAGTATAGGTGGACATGTCCATGGTTTT & TACTCGAGTATAGGTGGACATGTCCATGG-3' \\
\hline
\end{tabular}

\section{Lentivirus shRNA plasmid packing}

For transfection, $1 \mathrm{ml}$ DMEM, $10 \mu \mathrm{l}$ plasmid, $10 \mu \mathrm{l}$ Lenti-HG Mix and $60 \mu \mathrm{l} \mathrm{HG}$ transgene reagent (Qiagen, Germany) were mixed together at room temperature for 20 min, then added to $70-80 \%$ confluent 293 T cells (Life Sciences Institute of Chongqing Medical University, China), according to the manufacturer's protocol. Based on a QIAGEN Plasmid Packaging Midi Kit (Qiagen, Germany), titrate $120 \mu \mathrm{l} 100 \times$ Enhancing buffer after $12 \mathrm{~h}$. After incubation for $48 \mathrm{~h}, 293 \mathrm{~T}$ cells supernatant was filtered using $0.45 \mu \mathrm{m}$ cellulose acetate filters. Four different lentiviruses were collected and stored at $-80^{\circ} \mathrm{C}$ until further use.

\section{Cell transfection}

During logarithmic growth, SCC15 cells (Life Sciences Institute of Chongqing Medical University, China) were seeded into six well plates (NO.1 6) with 1.5 $\mathrm{ml}$ of DMEM/F12 supplemented with $10 \%$ fetal bovine serum (FBS). $500 \mu$ I PER1-shRNA-I, PER1-shRNA-II, PER1-shRNA-III and Control-shRNA, each containing $2.5 \mu \mathrm{l}$ Polybrene, were added to the first 4 wells. $500 \mu \mathrm{l}$ of serum-free DMEM/F12 were added to the remaining two wells. After $24 \mathrm{~h}$ incubation at $37^{\circ} \mathrm{C}$, in the presence of $5 \%$ $\mathrm{CO} 2$, fresh medium was added to the plate. The first five wells received DMEM/F12 containing $2 \mu \mathrm{g} / \mathrm{ml}$ puromycin, while the sixth well received serum-free DMEM/F12. Stably transfected cells were obtained after 7 days, and the culture medium was replaced every day. The transfectants were divided into five groups: three experimental groups expressing PER1-shRNA-I III, a Control-shRNA group expressing scramble shRNA, and an untreated SCC15 cell group (blank control group).

\section{Western blot analysis}

Exponential phase cells were lysed in RIPA buffer $[50 \mathrm{mmol} / \mathrm{L}$ Tris- $\mathrm{HCl}$ (pH 7.4), $150 \mathrm{mmol} / \mathrm{L} \mathrm{NaCl}, 0.5 \%$ NP-40] for $30 \mathrm{~min}$ at $0^{\circ} \mathrm{C}$. Cell lysates were collected using a cell scraper and centrifuged for 5 min $(12,000$ $\mathrm{rpm}, 4^{\circ} \mathrm{C}$ ), and then the supernatants were transferred to new tubes. Protein concentration was quantified using a BCA Protein Assay Kit according to the manufacturer's instructions (Beyotime, Jiangsu, China). The supernatants (50 $\mu \mathrm{g}$ protein) were subjected to SDS-PAGE, after which the proteins were transferred to polyvinylidene fluoride (PVDF) membranes (Millipore, USA), which were then blocked with 5\% non-fat dried milk for $1 \mathrm{~h}$. The membranes were then probed with rabbit polyclonal anti-hPER1 antibody (1:1000, Genetex, USA) and mouse monoclonal anti-hGAPDH antibody (1:3000, Zhongshan Golden-Bridge Biotechnology, China) for $2 \mathrm{~h}$ at room temperature. The membranes were washed three times in TBS, and then incubated with horseradish peroxidaseconjugated goat anti-rabbit IgG (1:5000, Zhongshan Golden-Bridge Biotechnology, China) at $37^{\circ} \mathrm{C}$ for $2 \mathrm{~h}$. The precipitated proteins were washed three times in TBS, and an ECL-advance Western Blot Detection System (Bio-Rad, California, USA) was used for detection and photography. The assays were done in triplicate.

\section{Flow cytometry assay}

Cells in logarithmic growth phase were harvested by trypsinization $(0.25 \%)$ and centrifuged for $5 \min (1000$ $\left.\mathrm{rpm}, 4^{\circ} \mathrm{C}\right)$, after which the supernatant was discarded and the cell pellets were washed twice with PBS and resuspended in PBS at a density of $1 \times 10^{6} \mathrm{cell} / \mathrm{s} / \mathrm{ml}$. (1) Detection of cell proliferation: cell suspensions $(1 \mathrm{ml})$ were centrifuged for $5 \mathrm{~min}\left(800 \mathrm{rpm}, 4^{\circ} \mathrm{C}\right)$, and the supernatants were discarded. Then, $70 \%$ ethyl alcohol $\left(-20^{\circ} \mathrm{C}, 1 \mathrm{ml}\right)$ was added to the cell pellets, repeatedly mixed, and incubated overnight at $4^{\circ} \mathrm{C}$. The cell suspensions were washed twice with PBS and resuspended in PBS $(1 \mathrm{ml})$. $1 \mathrm{ml}$ of propidium iodide solution was added to the cell suspensions and incubated for $30 \mathrm{~min}$ at $4^{\circ} \mathrm{C}$ in the dark. Proliferation was analyzed using FACSVantage flow cytometry (BD, New Jersey, USA), and the ModFit LT 2.0 program (Verity Software House, Topsham, Maine, USA) was used for fitting analysis. The following formula was used to calculate the tumor cells proliferation index (PI): $\mathrm{PI}=(\mathrm{S}+\mathrm{G} 2 / \mathrm{M}) /(\mathrm{G} 0 / \mathrm{G} 1+\mathrm{S}+\mathrm{G} 2 / \mathrm{M}) \times 100 \%$. (2) Detection of cell apoptosis: cell suspensions $(1 \mathrm{ml})$ were fixed in $70 \%$ ethyl alcohol for $2 \mathrm{~h}$, and then resuspended 
in Binding Buffer $(0.5 \mathrm{ml})$. The cell suspensions were incubated with $200 \mu \mathrm{l}$ of AnnexinV-FITC (Beyotime, Jiangsu, China) reagent for $15 \mathrm{~min}$ in the dark, and then stained with $1 \mathrm{ml}$ of propidium iodide solution for $2 \mathrm{~min}$ at room temperature in the dark. Apoptosis was analyzed using FACSVantage flow cytometry. The following formula was used to calculate the tumor cells apoptotic index (AI): $\mathrm{AI}=$ (number of apoptotic cells/total number of cells $) \times 100 \%$. Each experiment was carried out in triplicate.

\section{Quantitative real-time PCR assay (qRT-PCR)}

Total RNA was extracted from cells using RNAiso Plus (Takara, Kyoto, Japan). RNA concentration and quality were determined using a UV/Visible spectrophotometer (Amersham Biosciences, Goteborg, Sweden) to measure absorbance at $260 \mathrm{~nm}$ and $280 \mathrm{~nm}$. The RNAs were reverse transcribed by cDNA synthesis at $37^{\circ} \mathrm{C}$ for $15 \mathrm{~min}$ and $85^{\circ} \mathrm{C}$ for $5 \mathrm{~s}$. The qRT-PCR primers for CLOCK, BMAL1, PER1, PER2, PER3, DEC1, DEC2, $C R Y 1, C R Y 2, T I M, C K I E, R O R \alpha$, NPAS2 and REV-ERB $\alpha$ were designed using Oligo7.0 software, and are listed in Table 4. $\beta$-actin served as a normalization control. The reaction mixture for qPCR contained $12.5 \mu \mathrm{l}$ of $2 \times$ SYBR Premix Ex TaqTMII, $1 \mu$ of $0.4 \mu \mathrm{M}$ forward and reverse primers, $2 \mu \mathrm{l}$ of $50 \mathrm{ng} / \mu \mathrm{l}$ cDNA template and 8.5 $\mu \mathrm{l}$ double distilled $\mathrm{H}_{2} \mathrm{O}$ in a total volume of $25 \mu \mathrm{l}$. qPCR was performed using a C-1000TM Thermal Cycler (BioRad, California, USA). The PCR protocol entailed predenaturation at $95^{\circ} \mathrm{C}$ for $1.5 \mathrm{~min}$, and then amplification for 40 cycles, including denaturation for $10 \mathrm{~s}$ at $95^{\circ} \mathrm{C}$, and annealing extension for $30 \mathrm{~s}$ at $60^{\circ} \mathrm{C}$. The cycle threshold $(\mathrm{Ct})$ values were determined and normalized against the expression of $\beta$-actin in each sample. The data were analyzed using the $2^{-\Delta \Delta \mathrm{Ct}}$ method. The assays were done in triplicate.

\section{In vivo tumorigenicity assay}

Ten specific pathogen-free (SPF) BALB/c nu/ nu nude mice (females, 4-6 weeks old, 18-22 g) were purchased from the Experimental Animal Center of the Chongqing Medical University, and evenly divided into two groups of five mice each: PER1-shRNA-I (experimental group) and Control-shRNA (control group). During the logarithmic growth, PER1-shRNA-I and Control-shRNA cells were digested with $0.25 \%$ trypsin, centrifuged $\left(800 \mathrm{rpm}, 4^{\circ} \mathrm{C}\right)$ for $5 \mathrm{~min}$, and then serumfree DMEM/F12 was added to a final cell concentration of $1 \times 10^{7}$ cells $/ \mathrm{ml}$. The mice in the corresponding groups were then subcutaneously injected into the right back with 0.2 $\mathrm{ml}$ of cell suspension containing $2 \times 10^{6}$ PER1-shRNA-I or Control-shRNA cells. Three weeks later, noticeable tumors were present, and the mice were sacrificed by cervical dislocation. The tumors were immediately excised, washed with TBS, dried on filter paper and weighed using a precise balance (AA250, Denver Instrument, USA). Tumor size was measured using a caliper, and tumor volume was calculated using the formula $\mathrm{V}=0.5 \times \mathrm{a} \times \mathrm{b}^{2}$, where $\mathrm{a}$ is the longest diameter and $\mathrm{b}$ is the shortest diameter. The tumors were then divided equally into three parts. The first part was fixed in 4\% paraformaldehyde, embedded in paraffin blocks, and cut into $4-\mu \mathrm{m}$ slices. Routine HE staining was

Table 4: Primer sequences for clock genes used for quantitative real-time PCR

\begin{tabular}{|c|c|c|}
\hline Gene & Forward primer sequence & Reverse primer sequence \\
\hline PER1 & 5'-CTGCTACAGGCACGTTCAAG-3' & 5'-CTCAGGGACCAAGGCTAGTG-3' \\
\hline PER2 & 5'-TTGGACAGCGTCATCAGGTA-3' & 5'-TCCGCTTATCACTGGACCTT-3' \\
\hline PER3 & 5'-GCAGGTCTATGCCAGTGTGA-3' & 5’-ACCACCACCATTCGGTTCT-3' \\
\hline CLOCK & 5'-CAGCCAGTGATGTCTCAAGC-3' & 5’-ATGCGTGTCCGTTGTTCC-3’' \\
\hline$B M A L 1$ & 5'-TGCCACCAATCCATACACAG-3' & 5'-TTCCCTCGGTCACATCCTAC-3' \\
\hline$D E C 1$ & 5'-CAGCTTTCGGATGATGAAGG-3' & 5'-GCTGAAGGTGGGATCAGGTA-3' \\
\hline$D E C 2$ & 5'-GGGACCAACTGCTTCACACT-3' & 5'-TAATCTGTGGGACGGTAGGC-3' \\
\hline$C R Y 1$ & 5'-TGTGATTCGTGGACAACCAG-3' & 5'-TAGCTGCGTCTCGTTCCTTT-3’ \\
\hline$C R Y 2$ & 5'-AGGAGAACCACGACGAGA-3' & 5'-TCCGCTTCACCTTTTTATAC-3' \\
\hline CKIE & 5'-TGAGTATGAGGCTGCACAGG-3' & 5'-CTTCCCGAGATGGTCAAATG-3' \\
\hline$T I M$ & 5'-GATAGAGGCCCATTCCTGCAT-3' & 5'-GAAGGGCTGGGGAACTTAGAC-3' \\
\hline$N P A S 2$ & 5'-AACCTCGGCAGCACTTTAAC-3' & 5'-GGTTCTGACATGGCTGTGTG-3' \\
\hline$R O R \alpha$ & 5'-CТАТСССТСCAAGGCACAAG-3' & 5'-AACACAAGACTGACGAGCACA-3' \\
\hline$R E V-E R B \alpha$ & 5'-ACAGAATCGAACTCTGCACTTCT-3' & 5'-GGGGAGGGAGGCAGGTATT-3' \\
\hline$\beta$-actin & 5'-AGCGAGCATCCCCCAAAGTT-3' & 5'-GGGCACGAAGGCTCATCATT-3' \\
\hline
\end{tabular}


then performed, and the sections were observed under an optical microscope $(200 \times)$. The second part was analyzed by flow cytometry as described above to measure cell proliferation and apoptosis after tissue homogenization. The third part was tested by qRT-PCR as mentioned above to detect mRNA expression of CLOCK, BMAL1, PER1, PER2, PER3, DEC1, DEC2, CRY1, CRY2, TIM, CKI $\varepsilon$, ROR $\alpha$, NPAS 2 and REV-ERB $\alpha$ after tissue homogenization. This experiment was conducted in strict accordance with the recommendations of the Guide for the Care and Use of Laboratory Animals of the Chongqing Medical University. All animal experimental protocols were approved by the Ethics Committee of Chongqing Medical University (Permit Number: CQMU 2011-28).

\section{Statistical analysis}

All statistical analyses were performed using SPSS 19.0 software (IBM Corporation, Chicago, USA). Data are expressed as the mean $\pm \mathrm{SD}$. Comparisons between multiple groups were made using one-way analysis of variance (ANOVA). Comparisons between two groups were made using the least significant difference (LSD) test. Student's t-test was used to analyze differences between two groups of tumorigenesis assay. Values of $P<0.05$ were considered to be statistically significant.

\section{ACKNOWLEDGMENTS}

We thank H. X. Li for technical and statistical assistance. We also thank X. J. Fu, who volunteered her time to participate in certain of the experiments.

\section{CONFLICTS OF INTEREST}

The authors declare no conflict of interest in the work presented.

\section{REFERENCES}

1. Tan XM, Ye H, Yang K, Chen D, Wang QQ, Tang H, Zhao NB. Circadian variations of clock gene Per2 and cell cycle genes in different stages of carcinogenesis in golden hamster buccal mucosa. Scientific reports. 2015; 5:9997.

2. Ye H, Yang K, Tan XM, Fu XJ, Li HX. Daily rhythm variations of the clock gene PER1 and cancer-related genes during various stages of carcinogenesis in a golden hamster model of buccal mucosa carcinoma. Onco Targets Ther. 2015; 8:1419-26.

3. Storch KF, Lipan O, Leykin I, Viswanathan N, Davis FC, Wong WH, Weitz CJ. Extensive and divergent circadian gene expression in liver and heart. Nature. 2002; 417:78-83.

4. Siepka SM, Yoo SH, Park J, Song W, Kumar V, Hu Y, Lee C, Takahashi JS. Circadian mutant Overtime reveals F-box protein FBXL3 regulation of cryptochrome and period gene expression. Cell. 2007; 129:1011-23.

5. Shearman LP, Sriram S, Weaver DR, Maywood ES, Chaves I, Zheng B, Kume K, Lee CC, van der Horst GT, Hastings $\mathrm{MH}$, Reppert SM. Interacting molecular loops in the mammalian circadian clock. Science. 2000; 288:1013-9.

6. Honma S, Kawamoto T, Takagi Y, Fujimoto K, Sato F, Noshiro M, Kato Y, Honma K. Dec1 and Dec2 are regulators of the mammalian molecular clock. Nature. 2002; 419:841-4.

7. Preitner N, Damiola F, Lopez-Molina L, Zakany J, Duboule D, Albrecht U, Schibler U. The orphan nuclear receptor REV-ERBalpha controls circadian transcription within the positive limb of the mammalian circadian oscillator. Cell. 2002; 110:251-60.

8. Nakajima Y, Ikeda M, Kimura T, Honma S, Ohmiya Y, Honma K. Bidirectional role of orphan nuclear receptor RORalpha in clock gene transcriptions demonstrated by a novel reporter assay system. FEBS Lett. 2004; 565:122-6.

9. Cao Q, Gery S, Dashti A, Yin D, Zhou Y, Gu J, Koeffler HP. A role for the clock gene per1 in prostate cancer. Cancer Res. 2009; 69:7619-25.

10. Zhao N, Yang K, Yang G, Chen D, Tang H, Zhao D, Zhao C. Aberrant expression of clock gene period1 and its correlations with the growth, proliferation and metastasis of buccal squamous cell carcinoma. PLoS One. 2013; 8:e55894.

11. Zheng B, Albrecht U, Kaasik K, Sage M, Lu W, Vaishnav S, Li Q, Sun ZS, Eichele G, Bradley A, Lee CC. Nonredundant roles of the mPer1 and mPer2 genes in the mammalian circadian clock. Cell. 2001; 105:683-94.

12. Yang X, Wood PA, Ansell CM, Quiton DF, Oh EY, Du-Quiton J, Hrushesky WJ. The circadian clock gene Per1 suppresses cancer cell proliferation and tumor growth at specific times of day. Chronobiol Int. 2009; 26:1323-39.

13. Panda S, Antoch MP, Miller BH, Su AI, Schook AB, Straume M, Schultz PG, Kay SA, Takahashi JS, Hogenesch JB. Coordinated transcription of key pathways in the mouse by the circadian clock. Cell. 2002; 109:307-20.

14. Grundschober C, Delaunay F, Pühlhofer A, Triqueneaux G, Laudet V, Bartfai T, Nef P. Circadian regulation of diverse gene products revealed by mRNA expression profiling of synchronized fibroblasts. J Biol Chem. 2001; 276:46751-8.

15. Zhang R, Lahens NF, Ballance HI, Hughes ME, Hogenesch JB. A circadian gene expression atlas in mammals: implications for biology and medicine. Proc Natl Acad Sci U S A. 2014; 111:16219-24.

16. Green CB, Takahashi JS, Bass J. The meter of metabolism. Cell. 2008; 134:728-42.

17. Chen R, Yang K, Zhao NB, Zhao D, Chen D, Zhao CR, Tang H. Abnormal expression of PER1 circadian-clock gene in oral squamous cell carcinoma. Onco Targets Ther. 2012; 5:403-7. 
18. Gery S, Komatsu N, Baldjyan L, Yu A, Koo D, Koeffler HP. The circadian gene perl plays an important role in cell growth and DNA damage control in human cancer cells. Mol Cell. 2006; 22:375-82.

19. Krugluger W, Brandstaetter A, Kállay E, Schueller J, Krexner E, Kriwanek S, Bonner E, Cross HS. Regulation of genes of the circadian clock in human colon cancer: reduced period-1 and dihydropyrimidine dehydrogenase transcription correlates in high-grade tumors. Cancer Res. 2007; 67:7917-22.

20. Shih HC, Choo KB, Chang TJ, Yang MY, Shih MC, Yeh KT, Liu TC, Lin SF, Chang JG. Disturbance of circadian gene expression in endometrial cancer: detection by realtime quantitative RT-PCR. Oncol Rep. 2005; 14:1533-8.

21. Bae K, Jin X, Maywood ES, Hastings MH, Reppert SM, Weaver DR. Differential functions of mPer1, mPer2, and mPer3 in the SCN circadian clock. Neuron. 2001; 30:525-36.

22. Yang X, Wood PA, Ansell CM, Quiton DF, Oh EY, Du-Quiton J, Hrushesky WJ. The circadian clock gene Per1 suppresses cancer cell proliferation and tumor growth at specific times of day. Chronobiol Int. 2009; 26:1323-39.

23. Sato F, Nagata C, Liu Y, Suzuki T, Kondo J, Morohashi S, Imaizumi T, Kato Y, Kijima H. PERIOD1 is an antiapoptotic factor in human pancreatic and hepatic cancer cells. J Biochem. 2009; 146:833-8.

24. Li HX, Fu XJ, Yang K, Chen D, Tang H, Zhao Q. The clock gene PER1 suppresses expression of tumor-related genes in human oral squamous cell carcinoma. Oncotarget. 2016; 7:20574-20583. doi: 10.18632/oncotarget.7827.

25. Lee C, Etchegaray JP, Cagampang FR, Loudon AS, Reppert SM. Posttranslational mechanisms regulate the mammalian circadian clock. Cell. 2001; 107:855-67.

26. Richards J, All S, Skopis G, Cheng KY, Compton B, Srialluri N, Stow L, Jeffers LA, Gumz ML. Opposing actions of Per1 and Cry2 in the regulation of Per1 target gene expression in the liver and kidney. Am J Physiol Regul Integr Comp Physiol. 2013; 305:R735-47.

27. Kuo SJ, Chen ST, Yeh KT, Hou MF, Chang YS, Hsu NC, Chang JG. Disturbance of circadian gene expression in breast cancer. Virchows Arch. 2009; 454:467-74.

28. Clark SJ, Melki J. DNA methylation and gene silencing in cancer: which is the guilty party? Oncogene. 2002; 21:5380-7.

29. King DP, Zhao Y, Sangoram AM, Wilsbacher LD, Tanaka M, Antoch MP, Steeves TD, Vitaterna MH, Kornhauser JM, Lowrey PL, Turek FW, Takahashi JS. Positional cloning of the mouse circadian clock gene. Cell. 1997; 89:641-53.

30. DeBruyne JP, Weaver DR, Reppert SM. CLOCK and NPAS2 have overlapping roles in the suprachiasmatic circadian clock. Nat Neurosci. 2007; 10:543-5.

31. Reynolds A, Leake D, Boese Q, Scaringe S, Marshall WS, Khvorova A. Rational siRNA design for RNA interference. Nat Biotechnol. 2004; 22:326-30. 